\title{
CONSTRUCCIÓN CRÍTICA Y REALIDAD HISTÓRICA DE LA GENERACIÓN DEL 27
}

\author{
CRITICAL CONSTRUCTION AND HISTORICAL \\ REALITY OF THE GENERATION OF 1927
}

JuLio NeIRA JimÉNEZ

UNED

jneira@flog.uned.es

Fecha de Recepción: 07-07-2018

Fecha de Aceptación: 17-12-2018

\section{RESUMEN}

En este artículo se reconsideran y se desmienten algunas de las afirmaciones más consolidadas en la historia literaria actual sobre la Generación del 27: la celebración en diciembre de ese año en Sevilla de un homenaje a Luis de Góngora, con patrocinio del torero Ignacio Sánchez Mejías, que cerraría los actos de reivindicación del poeta barroco; la restricción de la generación a la poesía, como hecho distintivo de los nuevos escritores según Dámaso Alonso, y la amistad como factor aglutinante del grupo. Se aportan aquí numerosos argumentos documentales que permiten desmontar estas consideraciones como construcciones críticas infundadas y restaurar, así, la realidad histórica de ese riquísimo fenómeno que fue clave en la llamada Edad de Plata de la cultura española.

Palabras Clave: Generación del 27; homenaje a Góngora; Sevilla; amistades y enemistades; construcción crítica. 


\section{Abstract}

This article re-examines and questions some of the assertions that are most established in current literary history regarding the Generation of 1927: the celebrations in December that year in Seville in honour of Luis de Góngora, sponsored by bull-fighter Ignacio Sánchez Mejías, presumably as an end to a series of events vindicating the Baroque poet; the narrowing of the generation to poetry, as a defining characteristic of the new writers according to Dámaso Alonso, and friendship as the unifying force in the group. Extensive documentary evidence is offered here to undermine these claims as unfounded critical constructions, aiming to restore accuracy in the actual history of this rich phenomenon that was key in the so-called Silver Age of the Spanish culture.

Keywords: Generation of 1927; Tribute to Góngora; Seville; Friendship and Feud; Critical Construction.

En agosto de 1963 don Antonio Rodríguez Moñino pronunció el discurso Construcción crítica y realidad histórica en la poesía española de los siglos XVI y XVII ante la sesión plenaria del XX Congreso Internacional de la International Federation for Modern Languages and Literatures celebrada en Nueva York. En esa intervención, cuyo texto fue publicado dos años después (Rodríguez Moñino, 1965), el filólogo extremeño explicaba cómo la historiografía y la crítica venían aplicando conceptos contemporáneos a la poesía de los siglos áureos que distorsionaban la realidad de cómo esta se había producido; de manera que, por ejemplo, el conocimiento que un autor tenía de la obra de otros poetas o grupos geográficamente distantes era mucho menor de lo que se venía afirmando, porque la difusión de la poesía fue mucho más limitada de lo que se suponía, lo que pone gravemente en cuestión la atribución de influencias mutuas. Es decir, Rodríguez Moñino alertaba del riesgo de adulteración de la verdad histórica que supone su reconstrucción desde presupuestos de una realidad posterior varios siglos.

He titulado mi artículo del mismo modo en homenaje a Rodríguez Moñino, pero sobre todo para reivindicar ese principio, que es válido para la lírica de los siglos XVI y XVII y para la literatura de todas épocas. Una premisa que debe presidir toda investigación filológica, y que las nuevas promociones de filólogos deben, a mi juicio, tener muy presente: hay que acudir siempre a las fuentes primarias, a la reconstrucción precisa de la realidad histórica, y tener cuidado con el acarreo de «sedimentos» que sobre ella van depositando sucesivas oleadas de interpretaciones críticas. Porque asumir sin cuestionamiento alguno lo que otros han afirmado antes respecto a los fenómenos literarios con el paso del tiempo puede conducirnos a una grave distorsión de su auténtica naturaleza. Es cierto, no obstante, que el conocimiento avanza gracias a las aportaciones sucesivas de investigaciones y estudios, que no pueden desconocerse; si no, estaríamos siempre partiendo de cero y la ciencia no progresaría. Pero no es menos cierto que de vez en cuando debemos contrastar con los datos históricos la veracidad de los resultados críticos, para depurar posibles construcciones infundadas. Con objeto de demostrar la necesidad de esta cautela básica se cuestionan algunas 
«verdades» historiográficas que parecen inobjetables, pero cuyo contraste documental demuestra inciertas, relativas a una época mucho más reciente, la llamada Generación del 27.

\section{LA FALACIA DEL HOMENAJE GONGORINO EN SEVILLA}

Es sabido que la etiqueta "Generación de 1927", o sencillamente "el Veintisiete", es una de las que más éxito han tenido en las historias de la literatura española contemporánea desde al menos hace medio siglo. Pese a que diversos estudiosos (Rozas y Torres Nebrera, 1980; Fuentes, 1996; Anderson, 2005; Bernal, 2011; Neira, 2014, etc.) han puesto de manifiesto su inexactitud científica, parece imposible erradicarla del imaginario de los medios culturales y de la terminología publicitaria del sistema editorial. El problema no parece tanto el nombre —utilizado por vez primera por Juan Chabás en Nueva historia manual de la literatura española en su edición de 1944 (Anderson, 2005:121) y discutido hasta la década del 70 - como el significado que se otorgue al concepto. Y este fue establecido, sobre todo, a partir del artículo «Una generación poética, 1920-1936», publicado por Dámaso Alonso en 1948 en el número inicial de la revista Finisterre, y recogido luego en su libro Poetas españoles contemporáneos (1952).

Desde su autoridad de protagonista y su prestigio de catedrático de la Universidad Complutense, Dámaso Alonso fijó una serie de parámetros que definían como generación al grupo de poetas jóvenes que se dieron a conocer en la década de los 20 . Uno de los que la crítica ha venido repitiendo después como hito fundacional de tal «generación» o «grupo poético» (González, 2005: 195-198) —no me detendré ahora en la diferenciación de ambos conceptos, más general uno y específico el otro - fue la actividad colectiva que desarrollaron en reivindicación del poeta cordobés don Luis de Góngora, realizada en actos lúdicos en Madrid el 23 de mayo de 1927, fecha del tercer centenario de su muerte, y de índole más académica durante aquella primavera en Córdoba, aunque de estos apenas se ha hablado (Bernal, 2011: 81-87). Por el contrario, sí se ha escrito y mucho de la jira que siete de esos jóvenes autores hicieron a Sevilla entre el 15 y el 18 de diciembre de 1927 para participar en un supuesto homenaje del Ateneo de esa ciudad.

Tal interpretación del sentido de aquel acto se ha asentado como lugar común en la historiografía actual y sigue vigente de forma mayoritaria en nuestros días. Veamos dos ejemplos recientes. Uno es el artículo de Ángel Luis Prieto de Paula «Cómo se hace una generación» publicado el 9 de septiembre de 2017 en el número dedicado por Babelia, el suplemento cultural del diario El País, al nonagésimo aniversario del año generacional, bajo la rúbrica general «La generación del 27 en obras». Allí Prieto de Paula (2017) afirma: «Los fastos del tricentenario culminaron en diciembre de 1927, con los actos patrocinados por Ignacio Sánchez Mejías en Sevilla, adonde el torero llevó a sus amigos poetas y los tuvo a pan y manteles». No se entienda esta mención como crítica a poeta y profesor tan admirado y querido como Prieto de Paula, nada más lejos de mi intención. Él no hace sino repetir como tantos otros un lugar común en los estudios literarios: que aquella reunión de Sevilla fue el colofón del homenaje al poeta barroco. Otro ejemplo. El poeta José Manuel Caballero Bonald en su último libro, el de semblanzas Examen de in- 
genios, al hacer la de Dámaso Alonso y recordar su éxito en la reivindicación de Góngora, afirma:

Ese triunfo poético también fue —no es vano recordarlo- el motivo fundacional de la generación del 27, pues ese mismo año, es decir, tres siglos después de la muerte de Góngora, aquel grupo de amigos lo conmemoró en Sevilla e inició allí un recorrido triunfante por la literatura española del siglo XX” (Caballero Bonald, 2017: 53)

En verdad, esa afirmación de que los actos del Ateneo de Sevilla — que no se celebraron en el Ateneo, entonces en obras, como ya es bien sabido, sino en la sede de la Real Sociedad Económica de Amigos del País en la calle Rioja- consistieron en un homenaje de los jóvenes poetas a Góngora, es tan plausible dados los reconocidos trabajos filológicos sobre Góngora y el gongorismo del propio Dámaso Alonso, los homenajes poéticos que revistas como La Rosa de los Vientos, Litoral, Verso y prosa, etc. venían realizando a lo largo del año, así como el programa de ediciones elaborado por una comisión creada en la primavera de 1926 por ese grupo de jóvenes, que no parece rebatible. No lo cuestiona, sino todo lo contrario, Andrés Soria Olmedo (1997, 2007, 2010). Incluso Manuel Bernal, que ha querido desentrañar «la invención» de la generación del 27 y ha repasado en detalle la prensa sevillana de aquellos días, afirma: «Nuestros poetas habían llegado a la capital de la poesía el 15 de diciembre, un día antes de la celebración del homenaje a Góngora» (Bernal, 2011: 117), dando este por cierto. Mas esa idea de colofón de una serie de homenajes celebrados a lo largo del año parece presuponer una coordinación organizativa al modo de las conmemoraciones celebradas por instituciones públicas como las que recordaron el centenario de los poetas del 27 entre 1996 (Gerardo Diego) y 2005 (Manuel Altolaguirre) con exposiciones, congresos y ediciones. Pero nada de esto existía en 1927. Es una visión errónea porque se hace desde una perspectiva anacrónica.

Entiéndase bien que no se pretende aquí negar la realidad de un ambiente gongorista desde al menos 1923 y hasta principios de 1928, ni por supuesto obviar la importancia de la reivindicación del paradigma como poeta de Góngora para la configuración estética de la nueva literatura que se fragua en esos años decisivos, ni tampoco menospreciar los numerosos ejemplos de textos poéticos producidos por los jóvenes del 27 siguiendo ese paradigma, desde la décima de Jorge Guillén «El ruiseñor» a la Fábula de equis y zeda de Gerardo Diego y, aún más allá de 1930, las octavas reales de Perito en lunas de Miguel Hernández. Compartimos el criterio de Juan Manuel Rozas y Gregorio Torres, que afirmaron en 1980:

La vuelta al Barroco es el reencuentro con una literatura - maternal y a la vez fraternaque encierra unas profundas razones estéticas, nada anecdóticas, que se concentran en tres caracteres: la libertad de la imaginación y el ingenio, la supremacía de la metáfora y la autosuficiencia del hecho literario hacia un claro elitismo y una cierta deshumanización (Rozas y Torres, 1980, I: 14).

Lo que sí cuestionamos y negamos es que las jornadas de diciembre de 1927 en Sevilla tuvieran tal carácter apologético de don Luis de Góngora, como demuestra una revisión minuciosa de los testimonios de protagonistas o asistentes en aquellas dos jornadas (Gerardo 
Diego, Dámaso Alonso, Rafael Alberti, Jorge Guillén Juan Chabás, la prensa sevillana) y sus correspondencias (Morelli, 2001). Es más: demuestran que no se le mencionó fuera de la lectura de fragmentos de las Soledades que hicieron Federico García Lorca y Rafael Alberti y de la conferencia inicial de Dámaso Alonso, anunciada por la prensa sevillana como «Altitud poética de la literatura española» — publicada con el título «Escila y Caribdis de la literatura española» en 1944-, donde se cita al cordobés como a otras ilustres cimas de nuestra lírica: Garcilaso, Herrera, etc. Por el contrario, aquellas jornadas tuvieron un carácter afirmativo de la nueva literatura. Más que reivindicación del pasado de la poesía española, lo que se produjo fue la exaltación de un presente y de un futuro que quería romper con la tradición, igual que Góngora rompió con ella en el siglo XVII. Ese fue el auténtico significado de aquel considerado «hito generacional». Vayamos a los datos.

Pocos meses después Gerardo Diego publicó una jocosa crónica de aquellos días en Lola, el suplemento satírico de su revista Carmen. Se inicia así:

Una alegre jira de siete amigos —la «brillante pléyade», que había de decir un periódico local-a la siempre despierta y admirable Sevilla, invitados amablemente por el Ateneo, había de rematarse con una conmovedora ceremonia que no se había repetido en la península desde los tiempos trovadorescos de Quintana y Zorrilla: la solemne, triunfal coronación de Dámaso Alonso en la Venta de Antequera. (Diego, 1928: 1).

Luego, añade:

En Sevilla, a la que nombramos por méritos propios, históricos y vivos, capital de la poesía española, actuamos dos noches seguidas ante un grupo de hispálicos amigos que soportaron nuestros alegatos —en prosa y en verso-con heroica entereza (Diego, 1928: 2).

Repasa Diego las intervenciones de todos los participantes (además de Dámaso Alonso y del propio Diego, Juan Chabás, José Bergamín, Federico García Lorca, Rafael Alberti, Jorge Guillén) y los acontecimientos lúdicos de la comida en la Venta de Antequera al día siguiente, durante la que Ignacio Sánchez Mejías depositó sobre la cabeza de Dámaso Alonso una auténtica corona de laurel, con motivo de la noticia de que la Real Academia Española le había otorgado el premio nacional de literatura, dotado con 3.000 pta. (Bernal, 2011: 151). Pero no leemos ni una sola palabra sobre Góngora.

Al recordar aquella jira, lo que Dámaso Alonso escribió fueron estas palabras:

Eso era por los mediados de diciembre de 1927. El viaje a Sevilla había surgido de una invitación del Ateneo de esa ciudad. Y todo en realidad se debía al cariño (y sospecho que también a la esplendidez) de Ignacio Sánchez. Mejías. Nos habían aposentado en las mejores habitaciones de un hotel que nos pareció regio. Cuando se terminó, digamos, nuestra contrata, decidimos prolongar algunos días más nuestra estancia en Sevilla, y fue cuando ajustamos cuentas y vimos que, en aquel hotel, eran sólo las alturas lo que le iba bien a nuestros menguados fondos. (¿No acababa yo de hablar en el Ateneo sobre "La altitud poética de la literatura española»?). Abandonamos, pues, las suntuosidades del principal y nos instalamos ascéticamente en la buhardilla (Alonso, 1948: 194). 
Ninguna alusión, como se ve, tampoco al supuesto homenaje gongorista, ausente también del recuerdo que Rafael Alberti nos dejó desde Buenos Aires en La arboleda perdida, uno de los más citados:

Con quien Ignacio se encontraba realmente bien era con nosotros. Tanto que un día nos metió a todos en un tren y nos llevó a Sevilla. Al Ateneo. Había arreglado con su presidente, don Eusebio Blasco Garzón [...] una serie de lecturas y conferencias a cargo de los siete literatos madrileños de vanguardia, como nos llamó El Sol [...] Aquellas veladas nocturnas del Ateneo tuvieron un éxito inusitado [...] Federico y yo leímos, alternadamente, los más complicados fragmentos de las Soledades de dos Luis con interrupciones entusiastas de la concurrencia. Pero el delirio rebasó el ruedo cuando el propio Lorca recitó parte de su Romancero gitano, inédito aún (Alberti, 1975: 257-258).

Luego el gaditano relata con detalle lo ocurrido en la fiesta campera en la finca Pino Montano de Ignacio Sánchez Mejías, a la que los jóvenes poetas dedicaron más interés que a los actos ateneístas. Así lo presupuso Pedro Salinas, que en carta del 1 de diciembre anterior le cuenta a Jorge Guillén:

Mi opinión sobre esa aceifa lírica fue al principio adversa: Ateneo sevillano, Ignacio Sánchez Mejías, cosas que aunque ellas quieran tienen poco o nada que ver con la literatura. Pero desde el momento en que ya se planteó la cosa al modo de juerga sin lugar en donde [ilegible] me pareció factible. Y os doy mi fraternal bendición para la armada (Salinas / Guillén, 1992: 78).

Pero si las veladas de esos dos días, 16 y 17 de diciembre de 1927, no tuvieron el carácter de homenaje a Góngora que hasta ahora unánimemente se les ha atribuido, ¿en qué consistieron?, ¿con qué objeto se convocaron y se celebraron?

Para responder estas preguntas habremos de recurrir a las fuentes más directas y cercanas que conocemos, las crónicas periodísticas; y en concreto a la que escribió uno de los protagonistas de las jornadas, Juan Chabás, sin duda el testimonio personal más fiable, por conocer de primera mano su organización y desarrollo y por su cercanía a los hechos, pues se publicó apenas una semana después, el 24 de diciembre de 1927, en el diario madrileño $L a$ Libertad. Su lectura ofrece algunas sorpresas respecto a la versión comúnmente extendida. En ningún momento se menciona que el objetivo de la excursión y de los actos organizados por el Ateneo de Sevilla fuese homenajear a don Luis de Góngora en el tercer centenario de su muerte. Muy al contrario, Chabás afirma que se trató de la inauguración del curso de la sección de Literatura del Ateneo dedicada a la difusión de las nuevas tendencias literarias:

El Ateneo de Sevilla ha inaugurado el curso de su sección de Literatura; inaugurado juvenilmente, con fervoroso anhelo por conocer bien las nuevas tendencias del arte literario, y convertirlas, a lo largo de sus tareas en tema de estudio y discusión. El Sr. Blasco Garzón y el poeta D. José María Romero, presidentes, respectivamente, del Ateneo y de su sección de letras, hicieron constar esos propósitos al presentar al grupo de escritores que, con generosa esplendidez, había invitado aquella entidad para ese acto inaugural (Chabás, 1927: 6). 
No aparece ninguna mención a carácter reivindicativo alguno de la poesía del barroco cordobés, sino una presentación de la nueva literatura. Lo que explica que en sus palabras de salutación Blasco Garzón hiciera hincapié en esa condición de «ilustres representantes de la nueva literatura española» (Bernal, 2011: 134) de los invitados y no en la de especialistas en la obra de Góngora, a quien no mencionó, como ninguna de las crónicas de la prensa sevillana de esos días. Ya lo advirtió Rogelio Reyes: «ni en las notas de prensa ni en las intervenciones y discursos [...] se habla expresamente de homenaje a Góngora sino que más bien se pone una y otra vez el acento en la novedad literaria de los llegados de Madrid» (2007: 182). Y por más que este investigador arguye que entre los papeles personales de Romero Martínez, presidente de la sección de Literatura del Ateneo, Eloy Navarro Domínguez encontró un proyecto manuscrito de homenaje a Góngora consistente en un ciclo de conferencias en el que estaba prevista la intervención de Pedro Salinas, Rafael Alberti, José M. ${ }^{a}$ de Cossío, Adriano del Valle, Rogelio Buendía, su hermano Miguel Romero Martínez y el propio José M. ${ }^{a}$, la diferencia entre esta nómina y la que finalmente acudió a Sevilla es tan grande (solo coincide el nombre de Rafael Alberti) que viene a avalar nuestra tesis de que no fueron un homenaje a Góngora. Pudo existir el proyecto de organizarlo, pero desde luego no se realizó.

Hubo por tanto una voluntad de promoción generacional, pero no fundada en el rescate de Góngora, sino en lo que de nuevo tenía su creación literaria. Fue una propuesta orientada hacia el futuro y no hacia la recuperación del pasado, como por otra parte demuestra que a partir de 1928 prácticamente no se volviera a hablar de Góngora, de quien Dámaso Alonso y García Lorca pronto declararían estar cansados (Dehenin, 1990: 25-26). Rogelio Reyes también había apreciado:

Una atenta lectura de las reseñas de la prensa confirma [...] en sus intervenciones una evidente intención programática y una línea de pensamiento unitaria, producto, por supuesto, de la larga convivencia generacional y amistosa que espontáneamente los enlazaba a todos, pero también muy posiblemente de una concertada estrategia de utilizar la plataforma sevillana como caja de resonancia de esos ideales comunes, a modo de presentación pública y puesta en escena de una forma diferente y «nueva» de entender la creación literaria (Reyes, 2007: 176-177).

Ese carácter de autopromoción colectiva de la jira, a la que Chabás concede «cierto importante interés» se ve ratificado en el párrafo final de su reseña, que demuestra que ya por entonces, diciembre de 1927, los jóvenes poetas tenían una clara conciencia generacional:

Una nueva generación [...] Ha sido un acto colectivo - afirmación y concordia- de la juventud literaria. Aunque eran solo siete los expedicionarios, llevaban la representación directa de algunos más, y, sobre todo, fueron, no a un acto de ostentación personal, sino de información general. Como decía muy bien el presidente del Ateneo Sevillano, se trataba de abrir un nuevo curso, orientándolo para el trabajo de todo el año, hacia la total atención de nuestras letras jóvenes. Y como decía también Antonio Marichalar, en el saludo suyo que se leyó en Sevilla: «Esa gozosa jira constituye, a mi modo de ver, un acto afirmativo de una generación literaria» (Chabás, 1927: 6).

La segunda sorpresa que ofrece la reseña de Juan Chabás es que desmiente otra de las «verdades incuestionables» de la historiografía y de los testimonios autobiográficos sobre 
este viaje: la idea de que había sido posible gracias al presunto mecenazgo del torero Ignacio Sánchez Mejías, que habría pagado los gastos. Fue el Ateneo quien lo costeó, según hemos visto en el párrafo inicial de Chabás citado, que se reitera en el segundo: «Fuimos invitados, como refiero, por el Ateneo». Se confirma así la investigación de Rogelio Reyes (2007: 184), que encontró en el Libro de cuentas del Ateneo hispalense los asientos contables con las cantidades que costó a esa institución la celebración del encuentro: gastos de viaje: 1.300 pta., gastos de alojamiento: 745,60 pta. y «Suplido en el banquete»: 222 pta. Total: 2.267,60 pta. Cantidad considerablemente elevada para la época y la siempre precaria economía ateneísta. Lo que tal vez fuera la causa del cese de José M. ${ }^{a}$ Romero Martínez como presidente de la Sección de Literatura en marzo siguiente. Sí parece fuera de toda duda que corrió por cuenta de Sánchez Mejías la fiesta nocturna, juerga flamenca incluida, en su finca Pino Montano, de la que José Bergamín salió sin voz y al día siguiente tuvo que ser Dámaso Alonso quien leyera su conferencia.

Más sorpresas. Dámaso Alonso circunscribe a los poetas aquel momento espléndido de la cultura española. Recordemos que su artículo se tituló: «Una generación poética (19201936)», lo que sentó el patrón crítico de un canon exclusivamente poético compuesto por diez figuras. Sin embargo, la crónica de Chabás presenta un concepto generacional muy distinto, bastante más plural, plasmado en el programa de esos actos sevillanos. Hubo dos sesiones, una para la prosa y otra para el verso. La primera, el día 16 de diciembre, inaugurada por Dámaso Alonso, estuvo dedicada a la prosa, y en ella intervino Chabás con una conferencia sobre los prosistas jóvenes. La segunda sesión estuvo dedicada al verso y consistió en una conferencia de José Bergamín y otra de Gerardo Diego (la «Defensa de la estrofa» que publicó en su revista Carmen). Chabás anota que se leyeron diversas composiciones de autores como Pedro Salinas, Antonio Espina, Fernando Villalón, Luis Cernuda, y los presentes Gerardo Diego, Jorge Guillén, Federico García Lorca y Rafael Alberti. Además, menciona como asistentes entre el público a Adriano del Valle, Villalón y el grupo de la revista Mediodía (Llosent, Murube, Porlán, Collantes de Terán) y Luis Cernuda. En suma, una nómina mucho más amplia que la restringida que consagró Dámaso Alonso y mucho más cercana a la que los historiadores venimos reclamando en los últimos lustros. De hecho, en su crónica Chabás explica que estaban también invitados tres reconocidos prosistas: Antonio Espina, Melchor Fernández Almagro y Antonio Marichalar, que no pudieron acudir, aunque el último envió un saludo que se leyó en el acto.

Según hemos venido señalando, Rogelio Reyes estuvo muy cerca de comprender que el pretendido homenaje a Góngora financiado por Ignacio Sánchez Mejías es más una construcción crítica que una realidad histórica; y, sin embargo, pudo en él más la fuerza del lugar común historiográfico que las evidencias textuales de los documentos cuando afirmó:

El motivo de ese viaje a Sevilla en diciembre de 1927 no fue otro, al menos en el propósito inicial, que el de conmemorar el tercer centenario de la muerte del poeta cordobés Luis de Góngora, sumándose así al rosario de homenajes que venían sucediéndose en diferentes ciudades españolas (Reyes, 2007: 173).

Conviene reflexionar acerca de cómo pudo producirse esa construcción crítica contraria a los reiterados testimonios de los protagonistas, ninguno de los cuales atribuye a las jorna- 
das sevillanas la condición de homenaje a Góngora, que a lo sumo estuvo presente solo en el recitado por García Lorca y Alberti de versos de las Soledades, y en esa exclusiva dimensión lo recogió Elsa Dehenin (1962: 88) en su pionero estudio sobre el resurgir de Góngora en la generación del 27, que no corrigió en su reconsideración de 1990. En mi opinión no importa tanto saber donde comenzó el error y atribuir responsabilidades como entender el proceso que lo produjo.

En 1948 el recuerdo de los vínculos clásicos de esa generación, entonces escindida por la guerra y el exilio, proporcionaba una imagen de generación respetuosa con el pasado que resultaba más que conveniente en una sociedad cultural sometida a la dictadura de Franco, empeñada en ensalzar las glorias literarias del Siglo de Oro, lo que facilitaba el ejercicio de rehabilitación de aquellos poetas que Alonso pretendía; cuando en realidad lo que ellos admiraron fue el carácter innovador de la poesía de Góngora, el gran «vanguardista» de su época. Necesitado de un hecho generacional que cumpliese una de las características primordiales de la teoría clásica de las generaciones —adaptada por José Ortega y Gasset y Pedro Laín Entralgo a la española del 98-, un acontecimiento histórico aglutinante de sus miembros, Dámaso Alonso no podía entonces argüir, por razones obvias, ni la proclamación de la República en 1931 — el que más se hubiera acercado a la realidad histórica—, ni el inicio de la Guerra Civil, claramente disociador y tardío para las fechas generacionales. Cronológicamente 1927 encajaba, aunque la jira sevillana era un acontecimiento demasiado lúdico; de manera que definió la reivindicación de Góngora como aglutinador estético y las jornadas de diciembre como elemento cohesionador personal, aunque ni en ellas estuvieron todos aquellos que él mismo incorporó a la nómina generacional, ni siquiera por entonces todos ellos se conocían. Y como todos los recuerdos y memorias posteriores sobre aquellos años se referían con mucha contigüidad a los actos gongoristas de mayo y al viaje a Sevilla la dispar naturaleza de ambos acontecimientos acabó siendo confundida en una sola.

\section{LA FALACIA DE LA AMISTAD GENERACIONAL}

Del artículo de Dámaso Alonso acabaría derivándose aún otra construcción crítica incompatible con la autenticidad histórica: la de la amistad como formante generacional. Es cierto que en este caso los diversos testimonios personales contribuyeron a consolidarla, pero no lo es menos que, además de no ser una categoría literaria, hay numerosos argumentos documentales para desmentirla. Volvamos a «Una generación poética (1920-1936)», verdadera partida de nacimiento historiográfica, donde Dámaso Alonso recuerda la travesía de la barca que cruzó el Guadalquivir una de esas noches:

Imagen de la vida: un grupo de poetas, casi el núcleo central de una generación, atravesaba el río. La embarcación era un símbolo: representaba los vínculos y contactos personales que ligan a los miembros de un grupo en conjunta florescencia: la amistad, el compañerismo, los compartidos sentimientos, los mutuos influjos... (Alonso, 1948: 193).

Esa imagen idílica pretendía desde luego reivindicar el tiempo de la juventud, de una arcádica felicidad previa a la República y la guerra civil — lo que es mucho olvidar la dic- 
tadura de Primo de Rivera y sus muchas tensiones sociales - desde el presente siniestro de la posguerra que dio lugar a su libro Hijos de la ira (1944); un tiempo en el que, menos Gerardo Diego, Aleixandre y él mismo, casi todos aquellos escritores estaban o muertos (García Lorca, Hernández) o exiliados (Alberti, Altolaguirre, Bergamín, Cernuda, Chabás, Guillén, Moreno Villa, Prados, Salinas, etc.). Esa misma intención es la que llevó a Jorge Guillén a escribir su poema-crónica de aquellos días:

\section{UNOS AMIGOS}

(Diciembre de 1927)

¿Aquel momento ya es una leyenda?

Leyenda que recoge firme núcleo.

Así no se evapora, legendario

Con sus claras jornadas de esperanza,

Esperanza en acción y muy jovial,

Sin postura de escuela o teoría

Sin presunción de juventud que irrumpe,

Redentora entre añicos,

Visible el entusiasmo

Diluido en la luz, en el ambiente

De fervor y amistad.

Un recuerdo de viaje

Queda en nuestras memorias.

Nos fuimos a Sevilla.

¿Quiénes? Unos amigos

Por contactos casuales,

Un buen azar que resultó destino:

Relaciones felices

Entre quienes, aun mozos,

Se descubrieron gustos, preferencias

En su raíz comunes.

¡Poesía!

$Y$ nos fuimos al Sur.

Quedó en Madrid Salinas el Humano.

$Y$ también Aleixandre

- Con soledad tan fuerte de poeta.

$Y$ en Málaga otros dos, inolvidables.

Sevilla.

Y surgió Luis Cernuda junto al Betis.

(Plaza del Salvador.

En voz baja me dice:

Me gusta aquella imagen.

«Bien, radiador, ruiseñor del invierno.»)

Alberti, Rafael. Un torerillo

Que fuese gran espada. 
Intensamente Dámaso cordial,

Y su talento se prodiga a chorros.

Bergamín el Sutil,

Dueño en su laberinto. Sobra Ariadna.

Gerardo Diego en serio

Se lanza de repente a una cabriola.

Es un ;Hola! a su Lola.

Chabás — «con una voz como una barba»—

sonríe siempre desde su Levante.

Y Federico.

Ah, los hospitalarios sevillanos.

Allí Joaquín Romero a la cabeza,

Gran alcaide futuro de su Alcázar.

Compañía, risueña compañía.

Vivir es necesario,

Envidiar - ¿para qué?- no es necesario.

Se produce un acorde

Que sin atar enlaza.

Cada voz, ya distinta,

No se confunde nunca

- ¿Verdad, gran don Antonio? - con los ecos.

La vocación ejerce su mandato.

Coincidencia dichosa:

Madres hubo inspiradas,

y nacieron poetas, sí, posibles.

Todo estaría por hacer.

¿Se hizo?

Se fue haciendo, se hace.

Entusiasmo, entusiasmo.

Concluyó la excursión,

Juntos ya para siempre.

(Guillén, 2008, II: 1093)

En esa clave José Luis Cano (1970) propuso el nombre de «generación de la amistad» para el grupo. Es lo que José-Carlos Mainer ha llamado «la construcción de la Generación en el recuerdo» (Mainer, 1997: 194). Pero, como bien advirtió Ángel González, «la amistad como el grupo son el resultado de una compleja red de sutiles afinidades electivas que componen un entramado cohesivo más riguroso y racional» (González, 2005: 200). Como en todo grupo de personas que comparten actividad profesional o intelectual, en aquellos años hubo entre ellos muy buenos amigos —-Pedro Salinas y Jorge Guillén, Emilio Prados y Manuel Altolaguirre, Vicente Aleixandre y Dámaso Alonso-, pero también solo amigos que disputaban la primacía - García Lorca y Rafael Alberti-, conocidos — casi todos los demás- e incluso enemigos — el caso Cernuda, como veremos-. La realidad es que sobran 
datos de enemistad manifiesta, alguno de ellos producto de ese mismo artículo de Dámaso Alonso, para descartar la amistad como rasgo definitorio de aquel fenómeno literario.

Luis Cernuda leyó el estudio de Alonso durante su estancia en la escuela veraniega de Middlebury ese mismo 1948. Y le desagradó profundamente, pues interpretó que de nuevo era menospreciada su valoración como poeta en el seno del grupo, y desde su exilio norteamericano publicó una «Carta abierta a Dámaso Alonso» en el número 35 de la revista Ínsula. Texto que demostraba una intensa enemistad y que le generó un notable rechazo en el ámbito académico del exilio en Norteamérica, como estudian detenidamente José Teruel (2013: 65-84) y Antonio Rivero Taravillo (2011: 193-195). Lo que importa ahora no es tanto la disputa concreta que la inició — la disecciona también Bernal (2011: 129-133)— sino cómo se trasladó incluso a su poesía. En aquel acto de Sevilla Cernuda estuvo entre el público. Acababa de publicar su primer libro, Perfil del aire, era un poeta aún novel y sólo unos años después sería considerado uno más del grupo. Pero nunca olvidaría las críticas negativas a aquel primer libro, que le provocaron una actitud resentida hacia el ambiente poético desde el inicio. Tres años más tarde, intentaría obtener el puesto de lector de español en la Universidad de Cambridge que dejaba vacante Jorge Guillén. Al lectorado concurrió también Dámaso Alonso, dedicado ya plenamente a la investigación filológica, que lo ganó para disgusto de Cernuda, que nunca perdonaría la que interpretó como una desleal competencia. Mucho tiempo después la frase de Dámaso Alonso - a quien Cernuda consideraba «una pomposa nulidad», en carta a José Luis Cano del 5 de agosto de ese 1948 ((2003: 456) — en el artículo sobre la jira sevillana: «iQuién nos iba a decir, Federico, mi príncipe muerto, que para ti la cuerda se había de romper, brutalmente, de pronto, antes que para los demás, y que la marea turbia te había de arrastrar, víctima inocente!» (Alonso, 1948: 193-194) produjo en el poeta sevillano una violenta reacción, pues denunciaría en su poema «Otra vez, con sentimiento» del libro Desolación de la Quimera, el uso partidista que Alonso —y por extensión la «tribu literaria» de la España franquista— había realizado, según él, con el recuerdo del asesinado García Lorca:

Ya no creí que más invocaría

De tu amistad antigua la memoria

Que de ti se adueñó toda una tribu

Extraña para mí y para ti no menos

Extraña acaso.

Mas uno de esa tribu,

Profesor y, según pretenden él y otros,

De por allá (cuánto ha caído nuestra tierra),

Poeta, te ha llamado «mi príncipe».

$Y$ me pregunto qué hiciste tú para que ése

Pueda considerarte como príncipe suyo.

¿Vaciedad académica? La vaciedad común resulta

En sus escritos. Mas su rapto retórico

No aclara a nuestro entendimiento

Lo secreto en tu obra, aunque también le llamen 
Crítico de la poesía nuestra contemporánea.

La apropiación de ti, que nada suyo Fuiste o quisiste ser mientras vivías, Es lo que ahí despierta mi extrañeza. ¿Príncipe tú de un sapo? ¿No les basta A tus compatriotas haberte asesinado?

Ahora la estupidez sucede al crimen.

(Cernuda, 1993: 511)

Menos insultante, pero no menos dolorido, sería el poema del mismo libro dedicado por Cernuda a Pedro Salinas, con el título «Malentendu», que respondía a una larga serie de desencuentros entre ambos, iniciados con la aparición de su primer libro («Poco después cayeron sobre mí, una tras otra, las reseñas acerca de Perfil del aire: todas atacaban el libro. Pero lo que más me dolió fueron las cortas líneas evasivas con las cuales Salinas me acusó recibo desde Madrid», Cernuda, 1994: 629). El autor de La realidad y el deseo contestaría a las críticas con una larga exculpación en 1948, que tituló El crítico, el amigo y el poeta; pero nunca dejó de sentirse dolido con Guillén, a quien suponía, con acierto, causante de la actitud de Salinas. En cualquier caso, profundizar en esa polémica nos separaría mucho del objetivo de este estudio.

Mas lo que definitivamente colmó el memorial de agravios del sevillano fue el siguiente comentario de Salinas sobre él:

La afición suya, el aliño de su persona, el traje de buen corte, el pelo bien planchado, esos nudos de corbata perfectos, no es [sic] más que deseo de ocultarse, muralla del tímido, burladero del toro malo de la atención pública.

Por dentro cristal. Porque es el más licenciado Vidriera de todos, el que más aparta la gente de sí, por temor de que le rompan algo, el más extraño. (Salinas, 2007, II: 1306)

La expresión degradante de Salinas referida al personaje de la novela ejemplar cervantina del mismo título hubo de causar mucho daño a Cernuda. En realidad, respondía a una opinión largamente construida sobre el sevillano, que le parecía «tan desdeñoso, elegante e impertinente como siempre», según carta del 20 de noviembre de 1929 (Salinas / Guillén, 1992: 102). De ahí que la materialidad lingüística del poema complete por parte de Cernuda irónica y concluyentemente el catálogo de la enemistad y del encono: «inepcia» por tanta incomprensión, «desdén» ante la «amistad inocua», favoritismos, intereses personales..., hasta la ofensa que devuelve los insultos:

\section{MALENTENDU}

Fue tu primer amigo literario

(¿Amigo? No es palabra justa), el que primero

Te procuró experiencia en esa inevitable

Falacia de nuestro trato humano:

Ver cómo las palabras, las acciones 
Ajenas, son crudamente no entendidas.

Pues no quería o no podía entenderte,

Tus motivos él los trastocaba

A su manera: de claros

En oscuros y de razonables

En insensatos. No se lo perdonaste

Porque es imperdonable la voluntaria tontería.

Él escribió de ti eso de «Licenciado Vidriera»

$Y$ aun es de agradecer que superior inepcia no escribiese,

Siéndole tan ajenas las razones

Que te movían. ¿Y te extrañabas

De su desdén a tu amistad inocua,

Favoreciendo en cambio la de otros? Estos eran los suyos.

Los suyos, sus amigos predestinados,

Los que él entendía, los que a él le entendieron,

Si es que en el limbo entendimiento existe.

Por eso su intención, aunque excelente, al no entenderte,

Hizo de ti un fantoche a su medida:

Raro, turbio, inútilmente complicado.

(Cernuda, 1993: 524-525)

Tampoco la relación de Jorge Guillén con Cernuda fue nunca amistosa, desde el episodio inicial de Poesía de perfil (1927), cuyos poemas Guillén consideraba hechos a imagen y semejanza de los suyos y que fueron publicados antes que su Cántico (1928). Muchos años después en varias cartas Guillén trasmite a Salinas sus sentimientos hacia Cernuda. El 8 de marzo de 1949 le relata desde Wellesley College (EE. UU.):

Y a propósito ¿no te pareció impertinente la carta de Cernuda en Ínsula? Puesto ya a ser exquisito y elegante, más elegante habría sido sin protestar [...] Cernuda es cada día mejor poeta, pero como persona sigue siendo el mismo adolescente de Sevilla [...] Almorcé el otro día con Concha de Albornoz y una amiga suya (;A mí también me gustaba!) Y sin darme cuenta, se me escaparon mis confidencias de abuelo. Y Concha, simpática y casi ruborizada, me dijo: "iNo puede ser usted más diferente de Cernuda! No sé siquiera cómo pueden ustedes hablarse». (Cernuda se quejaba en Mount Holyoke recientemente: «¡Cada día me repugna más la familia!». "¿Pero cuál? Y las familias son quienes fabrican los muchachitos...») Yo concluí mentalmente; sí, somos muy distintos. ¿Qué tenemos que ver tú y yo con un marica? Como yo te escribo a ti y no a la posteridad — ¿para quién se escribe una carta?»-, me permito expresarme en el lenguaje de la conversación (Salinas / Guillén, 1992: 488)

Y en una carta del 14 de julio de 1951 se refiere a un último encuentro en México:

Le encontré en casa de Emilio Prados. Y me habló con tal saña de algunos amigos comunes que, sin responderle, di por terminada mi relación con él. Hubo claramente un rompimiento silencioso. Esta vez sentí una impresión que no era de antipatía. Cernuda - o «Cernida», como 
dice Moreno Villa, don José- no me es antipático, me repugna. ¡Cómo se parece a Juan Ramón! Sobre todo, en esto de transformar la amistad creciente en odio avanzado. He hecho cuanto he podido para lograr la amistad del sevillano. Vino a Wellesley, escribí -durante estos últimos meses-varias cartas de recomendación en favor suyo y, de repente... ;Lo mismo que J. R. J.! (Salinas / Guillén, 1992: 576).

Lo que no le cuenta es que la maledicencia de Cernuda tenía por objeto al propio Salinas, según contaba Claudio Guillén. En suma, ejemplos todos ellos de la enemistad manifiesta de Cernuda respecto a Salinas y Guillén.

La personalidad de Emilio Prados tampoco le facilitó una relación amistosa con los miembros del grupo. Él también tuvo momentos de mucho desánimo al no sentir correspondida su amistad, y también por la reseña de Gerardo Diego a su libro de poemas, Vuelta (1927). Tan abatido estaba que los amigos le organizaron un homenaje de desagravio en la revista Verso y prosa. Además, Prados se sintió traicionado cuando en 1928 Federico García Lorca, Rafael Alberti y Jorge Guillén publicaron sus libros Romancero gitano, Cal y canto y Cántico en la editorial de Revista de Occidente en lugar de en Litoral, como le habían asegurado, lo que hizo inviable el relanzamiento de su colección y posible el de la colección Los poetas, dirigida por Pedro Salinas, para disgusto del malagueño (Hernández, 1988, I: 36; Neira, 2007). Los tres poetas citados, además de Salinas, prefirieron publicar con una empresa fuerte y consolidada como Revista de Occidente, que les garantizaba una tirada mucho mayor, buena distribución comercial y derechos de autor, como los obtenidos por García Lorca con Romancero gitano, antes que dar sus obras en una colección artesanal, en la que los beneficios de un libro servían para editar el de un compañero que no tuviera recursos económicos disponibles. Prados recordaría treinta años después:

Acordamos — para la cuestión económica- ayudarnos unos a otros, de forma que con el producto del libro de cualquiera de nosotros (en mejor situación e[conómica]) se editaba el libro del que no podía pagarlo. ¡Así se constituyó nuestra amistad y se publicó nuestra poesía! Después se arruinó Litoral y fuimos creciendo» (Carreira, 1996: 59-60).

Más tarde, Prados se sintió igualmente abandonado cuando en 1931 quiso organizar un grupo surrealista. Viajó a Madrid, intentó convencer a Moreno Villa, Aleixandre, Cernuda, Alberti, etc., pero ninguno de ellos quiso acompañarle en esa aventura. Volvió desengañado a Málaga y se dedicó a un proyecto social de mejora de las condiciones de los pescadores de El Palo.

Pedro Salinas, por su parte, en sus cartas a Jorge Guillén —ese sí fue un ejemplo de amistad - siempre mantuvo una actitud reticente ante los poetas más jóvenes de este grupo generacional donde le encuadró la historiografía. En una escrita el 5 de abril de 1928 se queja de la acogida que le daban a Ignacio Sánchez Mejías:

Estoy absolutamente decidido a no admitir a ese nuevo compañero en literatura. No quiero decir, claro es, que salga él de la joven literatura, adonde le entran en hombros Alberti y Bergamín (Chabás echa una mano); no, me saldré yo. Antes que el contacto con la baja currinchería que todo eso representa. Estoy resuelto a hablar con Bergamín con toda claridad y amistad en 
cuanto haya ocasión. No con Alberti, que es irresponsable y como persona no me interesa, pero sí con Bergamín, que se está poniendo en ridículo (Salinas / Guillén, 1992: 86).

Con frecuencia, Salinas se indigna con los jóvenes. Se siente más cercano a la literatura de la generación anterior, la de los novecentistas (Ortega y Gasset, Gabriel Miró, Manuel Azaña, Ramón Pérez de Ayala, Benjamín Jarnés, e incluso Juan Ramón Jiménez, pese a su carácter), que a la de los jóvenes del 27, iconoclastas y estéticamente transgresores. Respecto a García Lorca, escribe a Guillén a propósito de la publicación del Manifiesto Antiartístico Catalán de Salvador Dalí, Luis Montayá y Sebastiá Gasch en el segundo número de la revista Gallo: «Anoche dije a Federico una sarta de atrocidades sobre todo ello. Creo que me excedí, pero la sagrada indignación me poseía. Estos jóvenes andaluces me van resultando cada día más giraldillos» (Salinas / Guillén, 1992: 87-88). La intención homófoba del calificativo se confirma en el comentario que Salinas hará a Guillén en una carta del 21 de febrero de 1931: «Federico siempre huido, entre esos amigos du côté de Charlus» (Salinas / Guillén, 1992: 133), en alusión al personaje homosexual de la novela de Marcel Proust Le côté de Guermantes que Salinas estaba traduciendo.

Acerca del estreno de La zapatera prodigiosa Salinas le confiesa a Guillén su negativa opinión sobre esta obra lorquiana el 11 de enero de 1931: «Yo, francamente, y entre los dos, me reservo. Cosita fácil, entretenida, con mucho color local, gracejillos, etc. Pero sin ninguna altura. Chiquillada. Lo de siempre» (Salinas / Guillén, 1992: 124). Y serán frecuentes sus alusiones a la pugna entre Lorca y Alberti por hacerse con el liderazgo generacional, lo que dibuja un escenario poco amistoso en el grupo. No parece que Salinas fuera el único que decía atrocidades a García Lorca. Jorge Guillén cuenta a su mujer Germaine Cahen en una carta del 14 de diciembre de 1927, la víspera del viaje a Sevilla: «anoche cené en la Residencia entre Alberti y Federico. ¡Qué cosas se dijeron, qué cosas feroces dijo Alberti a Lorca!» (Guillén, 2010: 667). Salinas observaría un año después, al informar a Guillén el 21 de diciembre de 1928 de una lectura pública de Sobre los ángeles de Alberti: «Ah, Federico no fue. La rivalidad se ahonda» (Salinas / Guillén, 1992: 94). Pero tampoco era mejor la opinión de Salinas sobre Alberti, pues comenta a propósito de su «huida» a Mallorca con María Teresa León en enero de 1931: «Rafael ha desaparecido sin decir nada ni en su casa [...] El niño, claro es, va con todo pagado, y corona así su historia moral. A mí de todos me ha gustado el rasgo, porque me indica que hay algo para Alberti superior a la vanidad y al deseo de éxito. Lo malo es el algo.» (Salinas / Guillén, 1992: 124). «Los niños» llama a Alberti y a García Lorca en carta del 20 de febrero de 1931.

Una carta de Vicente Aleixandre a Dámaso Alonso del 23 de octubre de 1929 deja en evidencia las tensiones que se producían entre los miembros del grupo, todo ello bien lejos de la arcadia amistosa que luego pretendieron reconstruir:

Estos días pasados he salido algo en plan de «joven literato». Ha estado aquí José María Hinojosa, me ha llamado y le he acompañado bastante. Con este motivo he visto a Alberti, Bergamín, Cernuda, Benjamín Palencia, etc. Esta salida, como otras, al campo de las pasioncillas literarias ha servido para asquearme. Como siempre, veo envidias de unos y otros, malquerencias, feos gestos, toda la lira. Una mañana en Cock (donde tú y yo el invierno pasado íbamos después de nuestros almuerzos juntos) fue ejemplar. Allí Alberti, Villalón y Bergamín y Cer- 
nuda se dijeron feas cosas, los tres primeros contra el último. Este, intransigente, poco menos que excomulgó literariamente a los otros. La reunión era para fundar un libelo o panfleto contra (siempre contra) el 900, etc. Acabó como el rosario de la aurora.

Y no son menos reveladores los comentarios acerca del recíproco distanciamiento respecto a Pedro Salinas:

Te informaré de la última palabra. La juventud empieza a llamar viejo a Salinas (esto te lo digo conjurándote a que no se lo cuentes). Empieza a estar fuera de su férula, así como de la de Guillén. Es verdad, el fenómeno es curioso. La última palabra literaria, por una coincidencia de los espíritus, habla un lenguaje en el que el acento de Guillén o el de Salinas no puede percibirse ya. Esto es innegable. Las cosas que hace Alberti, como Cernuda, como yo, como todos los que van apareciendo, tienen un tono distinto. Hay como un neorromanticismo en el ambiente, que utilizando la experiencia viva del superrealismo, se aleja de la poesía intelectual, de la poesía pura, de la poesía construida. En una palabra, Valéry y Juan Ramón están a un millón setecientas mil leguas de lo que empieza a iniciarse, y por lo tanto el magisterio de Salinas y de Guillén periclita por momentos. Un joven ha llegado a decide a Salinas: «Es natural que lo de usted o ustedes sea distinto: usted tiene otra edad». La vanguardia, la nueva vanguardia, empieza ya a señalar a esos mayores diciendo: creo que no es la juventud ya. Y no son los años: es el tono el que varía (Aleixandre, 2002: 730-731).

Manuel Bernal recoge otro testimonio de la falta de sintonía de los jóvenes con Pedro Salinas. Se trata del comentario despectivo que hizo Juan Guerrero Ruiz en el documental de Rafael Garza sobre el grupo. Se le oye decir en la filmación:

Hace tiempo que le tengo encargado a Ramón Gaya que haga un retrato de Juan Ramón. Este tiene un proyecto de retrato de Lorca, Cernuda, Altolaguirre y Aleixandre. El primero sentado al piano y los otros en torno a su figura. Cuando les pregunté si les gustaría incluir a Salinas se opusieron rotundamente. ¿Cómo es posible retratarnos con ese bisonte? De ninguna manera (Bernal, 2011: 128-129).

Recuérdese que en diciembre de 1927 Salinas contaba 36 años, mientras García Lorca, Aleixandre y Dámaso Alonso 29, y Cernuda y Alberti — que los cumplió en Sevilla aquel 16 de diciembre - 25. La diferencia de edad parecía abrir una grieta en la cohesión del grupo. Salinas fue el único que no colaboró en la revista Litoral y ya hemos visto que no fue a Sevilla. Parecía rechazar los acontecimientos más lúdicos y juveniles.

Permítaseme un último y breve ejemplo. Se suele afirmar que fue la antología de Gerardo Diego (1932) la que estableció el canon generacional (con el añadido de Juan Larrea y Fernando Villalón). Sin embargo, se obvia que fue Ángel Valbuena Prat en su librito $L a$ poesía española contemporánea (Madrid, CIAP, 1930) el primero en trazar dos años antes en el capítulo, «Las últimas tendencias», un panorama bastante aproximado al que ha consolidado la historiografía más reciente. Menciona Valbuena la importancia del Ultraísmo en la génesis de la nueva poesía (con sus revistas y sus principales autores) y se ocupa de los «poetas de hoy» Gerardo Diego, Federico García Lorca, Rafael Alberti, Dámaso Alonso, Pedro Salinas, Jorge Guillén, y los de la «más nueva generación de poetas»: Cernuda, Prados, Altolaguirre y Aleixandre. Es decir, los diez del canon con los añadidos de Ramón de 
Basterra y Antonio Espina, tan próximos entonces, y la mención como revelación de Antonio Obregón y su libro El campo, la ciudad, el cielo, que luego no tendría continuidad poética. Menciona también otros poetas «menores», encabezados por Chabás, Bacarisse, Garfias y Eugenio Montes, y a las poetas Josefina de la Torre, Ernestina de Champourcin y Concha Méndez Cuesta. Asombrosamente ajustado a la visión de un 27 plural que hoy podemos construir. Merece nuestro reconocimiento por un análisis tan temprano como acertado del universo poético español de la época.

Estos casos deben hacernos reflexionar sobre cómo las supuestas verdades críticas más consolidadas ofrecen un campo no menor de, digamos, incertidumbre. La «autoridad» crítica en ocasiones se ve contaminada por adherencias poco exactas que sin embargo se han asumido sin más y se imponen por la fuerza de la costumbre. En la investigación filológica conviene tener cierto grado de insumisión y no dar por sentado nada. Cuestionémonos lo sabido, verifiquemos los datos, comprobemos los documentos y no contribuyamos a consolidar las falacias heredadas.

Madrid, mayo de 2018

\section{BIBLIOGRAFÍA}

AleiXandre, Vicente (2002), Prosas completas, Ed. de Alejandro Duque Amusco, Madrid, Visor. Alonso, Dámaso (1948), «Una generación poética (1920-1936)», Finisterre, I, pp. 193-200.

Anderson, Andrew A, (2005), El Veintisiete en tela de juicio, Madrid, Gredos.

Bernal, Manuel (2011), La invención de la Generación del 27, Jaén, Berenice.

Caballero Bonald, José Manuel (2017). Examen de ingenios, Barcelona, Seix Barral.

CANo, José Luis (1970), La poesía de la Generación del 27, Madrid, Guadarrama.

Carreira, Antonio (1996), «Cartas entre Emilio Prados y Camilo José Cela», El Extramundi y los papeles de Iria Flavia, V, Iria Flavia.

Cernuda Luis (1948), «Carta abierta a Dámaso Alonso», Ínsula, 35, noviembre, p. 3. En (Cernuda, 1994: 198-200).

- (1993), Poesía completa, Ed. de Derek Harris y Luis Maristany, Madrid, Siruela.

- (1994), Obra completa II. Prosa I, Ed. de Derek Harris y Luis Maristany, Madrid, Siruela.

- (2003), Epistolario, James Valender (ed.), Madrid, Residencia de Estudiantes.

Chabás, Juan (1927), «Resumen literario», La Libertad, 24 diciembre, pp. 6-7.

Dehenin, Elsa (1962), La résurgence de Góngora et la génération pétique de 1927, Paris, Didier.

— (1990), «El resurgimiento de Góngora y la generación del 27 —revisitado—», Palabras del 27, 4, pp. 23-26.

Diego, Gerardo (1928), «Coronación de Dámaso Alonso», Lola. Amiga y suplemento de Carmen, 5, pp. 1-3.

Fuentes, Víctor (1996), «Modernidad, nuevas tendencias y polémicas literarias en la España de los años 20», Mercedes Vidal Tibbits (ed.), Studies in honor of Gilberto Paolini, Madrid, Juan de la Cuesta, pp. 309-322.

GonZÁLEZ, Ángel (2005), La poesía y sus circunstancias, Barcelona, Seix Barral.

Guillén, Jorge (2008), Aire nuestro, Ed. de Óscar Barrero, Barcelona, Tusquets, 2 vols. - (2010), Cartas a Germaine, Ed. de Margarita Ramírez, Barcelona, Gutenberg.

Hernández, Patricio (1988), Emilio Prados: La memoria del olvido, Zaragoza, Prensas Universitarias, 2 vols. 
MAINER, José-CARLos (1997), «Alrededor de 1927. Historia y cultura en torno a un canon», Cristóbal Cuevas (ed.). El universo creador del 27. Literatura, pintura, música y cine, Málaga, Congreso de Literatura Española Contemporánea, pp. 185-202.

Morelli, Gabriel (2001), Gerardo Diego y el III centenario de Góngora: correspondencia inédita, Valencia, Pre-textos.

Neira, Julio (1978), Litoral, la revista de una Generación, Santander, La isla de los ratones.

- (2007), «Introducción e índices», Edición facsímile de Litoral, Madrid, Sociedad Estatal de Conmemoraciones Culturales.

- (2014), «El Veintisiete, hoy». La quimera de los sueños. Claves de la poesía del Veintisiete, Málaga, El toro celeste.

Prieto de PAula, Ángel Luis (2017), «Cómo se hace una generación», Babelia, 9 de septiembre, p. 4.

Reyes, Rogelio (2007), «"Un buen azar que resultó destino”. El homenaje a Góngora en el Ateneo de Sevilla», en Soria Olmedo, 2007, pp. 171-187.

Rivero Taravillo, Antonio (2011), Luis Cernuda. Años de exilio (1938-1963), Barcelona, Tusquets.

Rodríguez MoÑInO, ANTONIO (1965), Construcción crítica y realidad histórica en la poesía española de los siglos XVI y XVII, Madrid, Castalia.

Rozas, Juan Manuel y Torres Nebrera, Gregorio (1980), El grupo poético de 1927, Madrid, Cincel.

Salinas, Pedro (2007), Obras completas, Ed. de Enric Bou, Madrid, Cátedra, 3 vols.

Salinas, Pedro y Guillén, Jorge (1992), Correspondencia (1923-1951), Ed. de Andrés Soria Olmedo, Barcelona, Tusquets.

Soria Olmedo, Andrés (1997), ;Viva don Luis! Desde Góngora a Sevilla, Madrid, Residencia de Estudiantes.

- (2007), Una densa polimorfía de belleza. Góngora y el grupo del 27, Málaga, Centro Andaluz de las Letras.

- (2010), La Generación del 27. ¿Aquel momento ya es una leyenda?, Madrid, Sociedad Estatal de Conmemoraciones Culturales, Junta de Andalucía y Residencia de Estudiantes.

Teruel, José (2013), Los años norteamericanos de Luis Cernuda, Valencia, Pre-textos Fundación Gerardo Diego. 